\title{
Case Report: Importance of dietary modification in successful
}

\section{management of eosinophilic gastroenteritis [version 1; peer}

\section{review: 2 approved with reservations]}

\author{
Pujitha Kudaravalli (D1, Sheikh A. Saleem², Sana Riaz³, Bishnu Sapkota4 \\ ${ }^{1}$ Internal Medicine, Upstate Medical University, Syracuse, New York, 13210, USA \\ ${ }^{2}$ Gastroenterology, Upstate Medical University, Syracuse, New York, 13210, USA \\ ${ }^{3}$ Internal Medicine, Upstate Medical University, Syracuse, NY, 13210, USA \\ ${ }^{4}$ Gastroenterology, Veterans Affairs Medical Center Syracuse, Syracuse, New York, 13210, USA
}

V1 First published: 16 Oct 2019, 8:1761

https://doi.org/10.12688/f1000research.20520.1

Latest published: 16 Oct 2019, 8:1761

https://doi.org/10.12688/f1000research.20520.1

\section{Abstract}

Introduction: Eosinophilic gastroenteritis (EGE) is an extremely rare inflammatory disorder with an estimated prevalence of 22-28/100 000. We herein, present a case of EGE in an elderly patient which was successfully managed with dietary restriction.

Case report: A 70-year-old male with a history of gastroesophageal reflux disorder (GERD), atopic dermatitis and asthma presented with 2 weeks history of foul-smelling non-bloody diarrhea associated with nausea, vomiting and weight loss. Physical examination was significant for dry oral mucosa and loss of skin turgor.

Lab findings were significant for a hemoglobin of $13.2 \mathrm{~g} / \mathrm{dl}$, hematocrit of $38.5 \%$, mean corpuscular volume of $86.3 \%$, white blood cell count of $24,200 / \mathrm{mm} 3$, albumin of $2.2 \mathrm{~g} / \mathrm{L}$, stool fat of $70 \mathrm{~g}$, stool osmolar gap of 115, C-reactive protein 1.47. Erythrocyte sedimentation rate, HIV test were unremarkable. Infectious stool work-up was negative. Computed tomography of the abdomen was unremarkable. The mucosa appeared mildly inflamed on upper endoscopy and colonoscopy, and biopsies showed eosinophilic infiltration of the mucosal and muscular layers. A diagnosis of eosinophilic gastroenteritis was made after other causes such as parasitic infection, drug use and malignancy were ruled out. The patient was counseled on a six-food elimination diet which successfully resolved his diarrhea. The patient did not have any relapses with dietary modification on follow-up.

Discussion: The recurrence rate of EGE is $50 \%$. Steroids improve symptoms in $90 \%$ of cases but the recurrence rates are high. The type, dose and duration of steroid therapy is unclear. Sodium cromoglicate, ketotifen, and Montelukast are other proposed treatments, the results being inconclusive. Bowel resection is performed in intestinal obstruction, but medical therapy is needed as recurrence in other segments in common. Dietary modification, a therapy with no side-

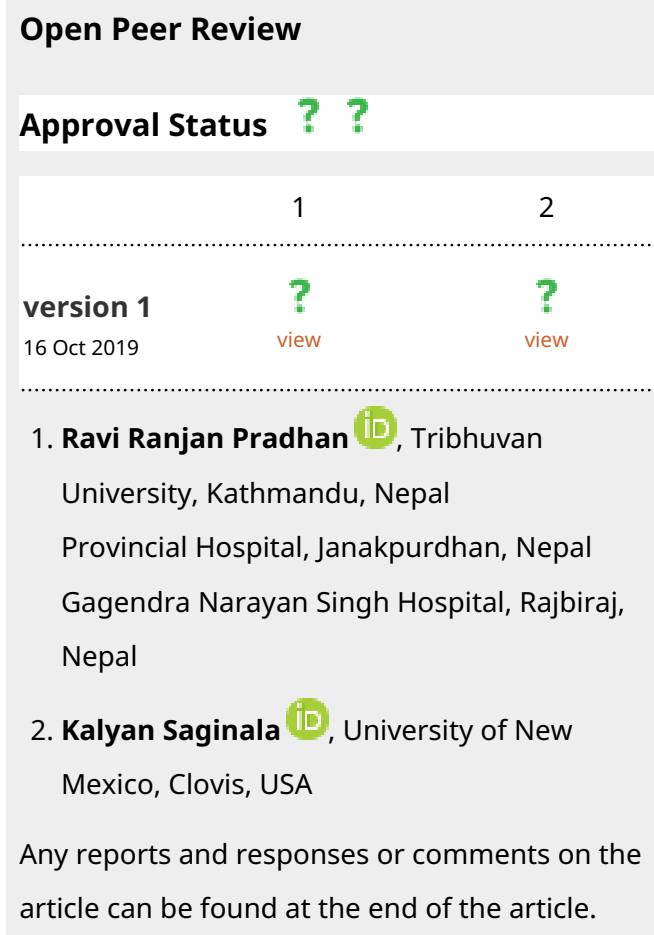


effects should be the first line of treatment as it can result in resolution sparing the patient of steroid induced side effects.

Keywords

Eosinophilic gastroenteritis, high recurrence, dietary modification, steroids, side effects

Corresponding author: Pujitha Kudaravalli (kudaravp@upstate.edu)

Author roles: Kudaravalli P: Writing - Original Draft Preparation, Writing - Review \& Editing; Saleem SA: Supervision, Writing - Review \& Editing; Riaz S: Writing - Review \& Editing; Sapkota B: Supervision, Writing - Review \& Editing

Competing interests: No competing interests were disclosed.

Grant information: The author(s) declared that no grants were involved in supporting this work.

Copyright: ( $\odot 2019$ Kudaravalli P et al. This is an open access article distributed under the terms of the Creative Commons Attribution License, which permits unrestricted use, distribution, and reproduction in any medium, provided the original work is properly cited.

How to cite this article: Kudaravalli P, Saleem SA, Riaz S and Sapkota B. Case Report: Importance of dietary modification in successful management of eosinophilic gastroenteritis [version 1; peer review: 2 approved with reservations] F1000Research 2019, 8:1761 https://doi.org/10.12688/f1000research.20520.1

First published: 16 Oct 2019, 8:1761 https://doi.org/10.12688/f1000research.20520.1 


\section{Introduction}

Eosinophilic gastroenteritis (EGE) is an extremely rare inflammatory disorder with an estimated prevalence of 22-28/100 000. We herein, present a case of EGE in an elderly patient which was successfully managed with dietary restriction. We would like to stress that food allergy is the main culprit in certain cases of EGE and dietary modification should always be the first step in the management of these cases ${ }^{1}$.

\section{Case presentation}

A 70-year-old male with a history of gastroesophageal reflux disorder (GERD), atopic dermatitis and asthma presented in August 2018 with 2 weeks history of foul-smelling non-bloody diarrhea associated with nausea, vomiting and weight loss. He did not have a family history of colonic disorders. He denied alcohol use, smoking or use of any other illicit drugs. Physical examination was significant for dry oral mucosa and loss of skin turgor.

\section{Investigations}

Lab findings were significant for a hemoglobin of $13.2 \mathrm{~g} / \mathrm{dl}$, hematocrit of $38.5 \%$, mean corpuscular volume of $86.3 \%$, white blood cell count of 24,200/mm3, albumin of $2.2 \mathrm{~g} / \mathrm{L}$, stool fat of $70 \mathrm{~g}$, stool osmolar gap of 115 , C-reactive protein 1.47. Erythrocyte sedimentation rate, HIV test were unremarkable. Infectious stool work-up was negative. Computed tomography of the abdomen was unremarkable. The mucosa appeared mildly inflamed on upper endoscopy and colonoscopy, and biopsies showed eosinophilic infiltration of the mucosal and muscular layers. A diagnosis of eosinophilic gastroenteritis was made after other causes such as parasitic infection, drug use and malignancy were ruled out.

\section{Treatment}

The patient was suggested a six-food elimination diet which included the elimination of soy, wheat, egg, milk, peanuts, and fish/shellfish and it successfully resolved his diarrhea.

\section{Outcome and follow up}

The patient was followed up in the outpatient GI clinic annually and did not have any relapses after dietary modification.

\section{Strengths, Limitations and Take Away Lessons}

Simple interventions like dietary changes can prevent recurrences and resolve symptoms in eosinophilic gastroenteritis. Although compliance to dietary changes can be challenging it is nonetheless an intervention without any side effects. The evidence for using steroids, type and duration of steroid therapy is not substantial to indicate its benefits. Use of biological agents in the treatment of EGE is still underway and hence the first line of intervention for the treatment of EGE should start with dietary modification.

\section{Discussion}

EGE most commonly affects males in the third decade of life and those with a history of eczema, asthma, allergic rhinitis. The prevalence of EGE is underestimated as it is under diagnosed given the rarity of the condition especially when it presents outside of the age spectrum like in our patient. The pathogenesis of EGE remains unclear and it is hypothesized to be a hypersensitive response to certain allergens. One proposed theory is that infectious and geographical factors interact with certain genetic variants causing esophagic dysbiosis which leads to Th2 cell immune response. Dysregulation of several genes termed EOE transcriptome is also shown to play a role ${ }^{2,3}$.

Laboratory findings seen in EGE include peripheral eosinophilia, elevated serum IgE levels, increased stool fat excretion, prolonged prothrombin time, hypoalbuminemia, anemia from intestinal malabsorption. Imaging can show thickening or nodularity of the antrum and thickened or saw tooth mucosa in the small bowel and when the muscular layer is involved irregular narrowing especially in the distal antrum and proximal small bowel can also be seen. EGE is a diagnosis of exclusion and other causes of hyperreactivity and eosinophilia should be considered such as parasitic infections, vasculitis disorders, reaction to drugs like enalapril, interferons, non-steroidal antiinflammatory drugs (NSAIDs), Helicobacter pylori infection ${ }^{4}$. The diagnosis of EGE is established when the biopsy shows more than expected numbers of eosinophils and all the other causes are ruled out.

Klein et al., classified EGE based on the depth of eosinophilic infiltration. Mucosal disease presents with abdominal pain, nausea/vomiting, diarrhea and the patients develop protein losing enteropathy, malabsorption and failure to thrive. Muscular involvement causes wall thickening and impaired motility which may lead to intestinal obstruction. Serosal disease presents as either isolated ascites or ascites in addition to the symptoms of serosal and muscular disease ${ }^{5}$.

The recurrence rate of EGE is $50 \%$ and a dietary trial could be a long-term solution like in our patient. A six-food elimination diet (soy, wheat, egg, milk, peanut/tree nuts, and fish/shellfish) or an elemental diet is recommended. Steroids improve symptoms in $90 \%$ of cases but the recurrence rates are high. The type, dose and duration of steroid therapy is unclear. The most commonly used regimen is prednisolone at 20 to $40 \mathrm{mg} / \mathrm{day}$, for 6 to 8 weeks including the tapering although most patients need a longer course due to relapses. Sodium cromoglicate, ketotifen, and Montelukast are other proposed treatments, the results being inconclusive. Bowel resection is performed in intestinal obstruction, but medical therapy is needed as recurrence in other segments is common ${ }^{6}$.

The use of biologics in the treatment of refractory EGE in being studied and could lead to new longer lasting results. Interleukin 5, an eosinophilic growth factor, is shown to play an important role in the pathogenesis of EGE. A few clinical trials assessing the use of anti- interleukin 5 in the form of humanized antibodies have shown improvement in endoscopic appearance, reduced clinical symptoms and improved quality of life while a few clinical trials showed no statistical 
difference in disease progression with this treatment. Trials to understand if eosinophils are key to the development and progression of eosinophilic esophagitis are underway ${ }^{8}$

\section{Conclusion}

The clinical guidelines for the diagnosis of EGE is sparse and the treatment offered is low-evidence based. Dietary modification, a therapy with no side-effects should be the first line of treatment and can result in resolution sparing the patient of steroid induced side effects.

\section{Consent}

Written informed consent for publication of their clinical details was obtained from the patient.

\section{Acknowledgements}

The case report has been accepted for a poster presentation at American College of Gastroenterology Conference in October 2019 at San Antonio, Texas.
1. Okimoto $\mathrm{E}$, Ishimura $\mathrm{N}$, Okada $\mathrm{M}$, et al:: Successful Food-Elimination Diet in an Adult with Eosinophilic Gastroenteritis. ACG case Rep J. 2018; 5(1): e38. PubMed Abstract | Publisher Full Text | Free Full Text

2. Lyles J, Rothenberg M: Role of genetics, environment, and their interactions in the pathogenesis of eosinophilic esophagitis. Curr Opin Immunol. 2019; 60: 46-53.

PubMed Abstract | Publisher Full Text

3. Cianferoni A, Spergel JM: Eosinophilic Esophagitis and Gastroenteritis. Curr Allergy Asthma Rep. 2015; 15(9): 58.

PubMed Abstract | Publisher Full Text

4. López-Medina G, Gallo M, Prado A, et al:: Eosinophilic Gastroenteritis: Case Report and Review in Search for Diagnostic Key Points. Case Rep Gastrointest Med. 2015; 2015: 239506

PubMed Abstract | Publisher Full Text | Free Full Text
5. Benatti C, Sacchetti C, Pedrazzi A, et al:: Eosinophilic gastroenteritis: a case report and a review of eosinophilic gastrointestinal disorders. Ital J Med. 2009; 3(3): 166-171.

Publisher Full Text

6. Sadeghi A, Abdi E, Jamshidfar N, et al.: Eosinophilic gastroenteritis; a report of two cases with different presentations. Gastoenterol Hepatol Bed Bench. 2017; 10(Supp1): S161-S164.

PubMed Abstract | Free Full Text

7. Temiz T, Yaylaci S, Demir MV, et al.: Eosinophilic gastroenteritis: a rare case report. N Am J Med Sci. 2012; 4(8): 367-368.

PubMed Abstract | Publisher Full Text | Free Full Text

8. Roufosse F: Targeting the Interleukin-5 Pathway for Treatment of Eosinophilic Conditions Other than Asthma. Front Med (Lausanne). 2018; 5: 49.

PubMed Abstract | Publisher Full Text | Free Full Text 


\section{Open Peer Review}

\section{Current Peer Review Status: ? ?}

\section{Version 1}

Reviewer Report 29 October 2021

https://doi.org/10.5256/f1000research.22554.r96347

(C) 2021 Saginala K. This is an open access peer review report distributed under the terms of the Creative Commons Attribution License, which permits unrestricted use, distribution, and reproduction in any medium, provided the original work is properly cited.

\section{Kalyan Saginala}

University of New Mexico, Clovis, NM, USA

1. Recommend to add pictures of upper EGD and colonoscopy with histo-pathological pictures as well if possible.

2. Family history not significant for gastrointestinal disorders would be better than stating as he did not have a family history of colonic disorders.

3. Would recommend to document Lab findings in tabular form with reference ranges as well.

4. Better to document what is the approximate duration time period when the symptoms diarrhea resolved.

Is the background of the case's history and progression described in sufficient detail? Partly

Are enough details provided of any physical examination and diagnostic tests, treatment given and outcomes?

Partly

Is sufficient discussion included of the importance of the findings and their relevance to future understanding of disease processes, diagnosis or treatment?

Partly

Is the case presented with sufficient detail to be useful for other practitioners? Partly

Competing Interests: No competing interests were disclosed.

Reviewer Expertise: epidemiology of cancers - bladder cancer, melanoma 


\title{
I confirm that I have read this submission and believe that I have an appropriate level of expertise to confirm that it is of an acceptable scientific standard, however I have significant reservations, as outlined above.
}

Reviewer Report 10 December 2019

\section{https://doi.org/10.5256/f1000research.22554.r57549}

(C) 2019 Pradhan R. This is an open access peer review report distributed under the terms of the Creative Commons Attribution License, which permits unrestricted use, distribution, and reproduction in any medium, provided the original work is properly cited.

\author{
Ravi Ranjan Pradhan \\ ${ }^{1}$ Internal Medicine, Institute of Medicine, Tribhuvan University, Kathmandu, Nepal \\ 2 Provincial Hospital, Janakpurdhan, Nepal \\ 3 Gagendra Narayan Singh Hospital, Rajbiraj, Nepal
}

Thank you for providing me an opportunity for peer review. I have the following comments and I think major revision is required for the article.

\section{Abstract:}

The authors should not mention all details like history, lab findings and discussion in the abstract. I think the abstract should be concise like this:

"Eosinophilic gastroenteritis (EGE) is an extremely rare inflammatory disorder with an estimated prevalence of 22-28/100 000. Steroids improve symptoms in $90 \%$ of cases but the recurrence rates are high, and patients are exposed to steroid-related side effects. We herein, present a case of EGE in an elderly patient who was successfully managed with dietary restriction. Dietary modification in patients with EGE is free of steroid-related side effects, and may be considered as initial therapy for EGE."

\section{Introduction:}

1. Add more in the introduction about EGE, discuss global scenarios and particular nation scenarios.

2. The line "Eosinophilic gastroenteritis (EGE) is an extremely rare inflammatory disorder with an estimated prevalence of 22-28/100 000." has no citation. Citation is advised.

\section{Case presentation:}

1. Don't mention the date (August 2018).

2. Describe more about diarrhea: the number of episodes per day, and color. Was it associated with pain in the abdomen? Was there nocturnal diarrhea?

3. Describe about vomiting. 
4. "family history of colonic disorders" - what does it mean? Colorectal ca or polyp? The authors are advised to mention it.

5. "Physical examination was significant for dry oral mucosa and loss of skin turgor." Write like: "Physical examination was significant except for dry oral mucosa and loss of skin turgor.

\section{Investigations:}

1. Remove this line: "Lab findings were significant for a". Rewrite like: "on investigation hemoglobin was...".

2. Write down important findings in sentence. Make a table for the investigations that shows detailed parameters:

- Parameters

- Reference range, adults

- On admission

- After dietary restriction

3. Infectious stool work-up was negative. Mention in detail what infectious work up was done.

4. Keep the endoscopy and colonoscopy photo.

5. Mention which site the biopsy was taken from - colon or esophagus?

6. Figure of histopathology is a must and will give the most convincing evidence.

7. Was endoscopy/biopsy done after dietary restriction? How can you presume that there was no inflammation going on after dietary restriction based on only improvement of clinical history?

\section{Follow up:}

1. How long was the patient followed up and after what time of dietary restriction did the patient show clinical improvement?

\section{Strengths, Limitations and Take Away Lessons:}

1. The authors are advised to remove this portion.

\section{Discussion:}

1. The discussion seems to be like the introduction and the authors are advised to include these paragraphs in the introduction section.

2. The discussion should include how this case report is similar to or different from other reports.

3. What is unique to this case report? 
4. What is unique in management? Discuss in detail.

Is the background of the case's history and progression described in sufficient detail? Partly

Are enough details provided of any physical examination and diagnostic tests, treatment given and outcomes?

No

Is sufficient discussion included of the importance of the findings and their relevance to future understanding of disease processes, diagnosis or treatment?

No

Is the case presented with sufficient detail to be useful for other practitioners?

Partly

Competing Interests: No competing interests were disclosed.

Reviewer Expertise: Internal medicine (cardio, gastro, neuro)

I confirm that I have read this submission and believe that I have an appropriate level of expertise to confirm that it is of an acceptable scientific standard, however I have significant reservations, as outlined above.

The benefits of publishing with F1000Research:

- Your article is published within days, with no editorial bias

- You can publish traditional articles, null/negative results, case reports, data notes and more

- The peer review process is transparent and collaborative

- Your article is indexed in PubMed after passing peer review

- Dedicated customer support at every stage

For pre-submission enquiries, contact research@f1000.com 